\title{
Pemanfaatan Lingkungan Sekolah Sebagai Sumber Belajar Konsep Keanekaragaman Hayati Menggunakan Model Inkuiri Terbimbing
}

\author{
Wiwin Febrianti, Aseptianova, Tutik Fitri Wijayanti* \\ FKIP Universitas Muhammadiyah Palembang \\ E-mail: fitri_wijayanti@live.com \\ diterima: 20 Agustus 2019, disetujui: 30 Agustus 2019, dipublikasikan: 30 September 2019.
}

\begin{abstract}
Abstrak
Penelitian ini bertujuan untuk mengetahui pengaruh pemanfaatan lingkungan sekolah sebagai sumber belajar dengan model inkuiri terbimbing terhadap hasil belajar Kognitif siswa. Metode penelitian ini adalah Quasi Eksperimen dengan desain penelitian Non equivalent control group design. Sampel yang digunakan adalah kelas X SMAN 4 Palembang. Teknik pengumpulan data yang digunakan dalam penelitian ini adalah Tes pilihan ganda yang berjumlah 24 soal untuk menilai kemampuan kognitif siswa. Teknik analisis data menggunakan Paired Sample t-Test. Hasil penelitian menyatakan pada kelas eksperimen dengan $(\alpha=0,05)$ didapatkan nilai signifikansi (2-tailed) 0,000. Dengan demikian, dapat disimpulkan bahwa pemanfaatan lingkungan sekolah sebagai sumber belajar dengan model inkuiri terbimbing memberikan pengaruh terhadap hasil belajar siswa pada konsep keanekaragaman hayati kelas X di SMA Negeri 4 Palembang.
\end{abstract}

Kata Kunci: lingkungan sekolah, sumber belajar, inkuiri terbimbing, hasil belajar.

\section{Using the School Environment as a Learning Resource for the Concept of Biodiversity Using the Guided Inquiry Model}

\author{
Wiwin Febrianti, Aseptianova, Tutik Fitri Wijayanti* \\ FKIP Universitas Muhammadiyah Palembang \\ E-mail: fitri_wijayanti@live.com \\ Accepted: August 20 $0^{\text {th }}$ 2019. Approved: August $30^{\text {th }}, 2019$, Published: September $30^{\text {th }}, 2019$
}

\begin{abstract}
This study aims to determine the effect of using the school environment as a learning resource with guided inquiry models on students' cognitive learning outcomes. This research method is Quasi Experiment with Non equivalent control group design. The sample used was class X SMAN 4 Palembang. The data collection technique used in this study was a multiple choice test with 24 questions to assess students' cognitive abilities. The data analysis technique used Paired Sample t-Test. The results stated in the experimental class with $(\alpha=$ 0.05) obtained a significance value (2-tailed) of 0,000. Thus, it can be concluded that the use of the school environment as a source of learning with the guided inquiry model gives an influence on student learning outcomes in the concept of biodiversity class X in SMA Negeri 4 Palembang.
\end{abstract}

Keywords: school environment, learning resources, guided inquiry, learning outcomes. 


\section{PENDAHULUAN}

Pembelajaran biologi merupakan pembelajaran yang mengajak siswa untuk menemukan konsep pemahaman melalui pengamatan langsung pada objek yang dipelajari secara sistematis dan juga merupakan suatu proses penyelidikan. Pelajaran Biologi adalah pelajaran yang menarik dan menyenangkan serta berkaitan dengan kehidupan sehari-hari. Agar pembelajaran biologi dapat terlaksana dengan baik dan tercapainya tujuan pembelajaran yang maksimal, maka siswa harus dapat memahami konsep-konsep materi yang diberikan guru pada saat proses pembelajaran (Kurniawan, 2013). Selanjutnya siswa dituntut untuk mampu mengembangkan hasil belajar berupa pengetahuan, keterampilan, dan sikap yang berperan untuk mengetahui sejauh mana tujuan-tujuan pembelajaran telah dicapai atau dikuasai oleh siswa yang diperlihatkannya setelah mereka menempuh proses belajar mengajar (Setiawan, 2008).

$$
\text { Hasil belajar merupakan }
$$

kemampuan yang diperoleh individu setelah proses belajar berlangsung, yang dapat memberikan perubahan tingkah laku baik pengetahuan, pemahaman, sikap, dan keterampilan siswa sehingga menjadi lebih baik dari sebelumnya (Sjukur, 2012). Hasil belajar bukan hanya berupa penguasaan pengetahuan, tetapi juga kecakapan dan keterampilan dalam melihat, menganalisis, dan memecahkan masalah, membuat rencana dan mengadakan pembagian kerja, dengan demikian aktivitas dan produk yang dihasilkan dari ativitas belajar ini mendapatkan penilaian (Brahim, 2007).

Kenyataan yang banyak dijumpai pada sekolah di Indonesia adalah pembelajaran yang berpusat pada guru ataupun hanya menggunakan metode ceramah. Kebanyakan siswa yang merasa bosan dan sulit untuk memahami materi pelajaran. Penguasaan materi saja tidak cukup untuk meningkatkan hasil belajar, serta memacu siswa untuk aktif dalam pembelajaran. Penyampaian materi selalu monoton yaitu dengan ceramah kemudian siswa diminta untuk mendengarkan dan mencatat materi pelajaran, hal-hal inilah yang menyebabkan partisipasi rendah dan hasil belajar yang kurang (Ramawati, 2016).

Berdasarkan pengalaman peneliti selama melaksanakan Program Pengalaman Lapangan (PPL) dan observasi dengan mewawancarai guru mata pelajaran biologi di di SMA Negeri 4 Palembang, peneliti menemukan beberapa masalah dan fakta yang terjadi pada siswa kelas X. Adapun masalah-masalah dan fakta tersebut yaitu 1) pada proses pembelajaran di kelas $\mathrm{X}$ belum mengukur nilai kognitif C5 dan C6 karena hanya mengukur nilai kognitif $\mathrm{C} 1$ sampai dengan C4 saja, 2) pada proses pembelajaran guru hanya mengukur nilai kognitif saja, sedangkan nilai afektif dan psikomotor siswa belum diukur, 3) pada proses pembelajaran di dalam kelas sedikit sekali yang mengajukan pertanyaan saat guru memberikan kesempatan kepada siswa untuk bertanya, 4) beberapa siswa sering mengobrol dengan teman sebangku, dan 5) siswa sering tidak memperhatikan penjelasan guru. Guru sudah berusaha menyampaikan materi dengan baik, dengan suara yang jelas, menatap semua siswa dan menegur siswa jika tidak memperhatikan. Upaya guru ini belum berhasil memotivasi siswa untuk mengikuti pembelajaran dengan serius. Guru menyadari belum menyelenggarakan proses pembelajaran materi keanekaragaman hayati dengan mengajak siswa untuk melakukan observasi 
atau pengamatan langsung ke lingkungan sekolah untuk menemukan fakta-fakta atau konsep-konsep keanekaragaman hayati. Permasalahan-permasalahan tersebut berimbas pada hasil belajar siswa di sekolah tersebut. Nilai siswa pada materi keanekaragaman hayati di kelas X MIPA 1 dan X MIPA 2 pada tahun 2016 tidak mencapai 50\% KKM. Nilai ujian nasional siswa pada mata pelajaran biologi juga tidak mencapai nilai KKM (Puspendik, 2017).

Pada pembelajaran keanekaragaman hayati guru belum mengoptimalkan lingkungan sekitar sekolah sebagai sumber belajar, yang diharapkan dapat meningkatkan hasil belajar siswa. Penelitian Nugroho \& Hanik (2016) menyatakan bahwa pembelajaran yang memanfaatkan lingkungan sekitar kelas (luar kelas) dapat meningkatkan hasil belajar kognitif. Pemanfaatan lingkungan luar kelas sebagai sumber belajar dapat diimplementasikan menggunakan model pembelajaran. Salah satu model pembelajaran yang dapat meningkatkan hasil belajar siswa adalah model pembelajaran inkuiri terbimbing. Model tersebut didasari oleh teori belajar penemuan yang menyarankan agar siswa hendaknya belajar melalui berpartisipasi aktif dengan konsep-konsep dan prinsipprinsip agar mereka memperoleh pengalaman dan melakukan eksperimeneksperimen yang mengizinkan mereka untuk menemukan konsep dan prinsip itu sendiri. Pada model tersebut siswa memperoleh pengalaman dan melakukan eksperimen dengan menyelidiki keanekaragaman hayati yang ada di lingkungan sekolah.

Model pembelajaran inkuiri terbimbing didasari oleh teori belajar penemuan yang menyarankan agar siswa hendaknya belajar melalui berpartisipasi aktif dengan konsep-konsep dan prinsipprinsip agar mereka memperoleh pengalaman dan melakukan eksperimeneksperimen yang mengizinkan mereka untuk menemukan konsep dan prinsip itu sendiri. Model pembelajaran inkuiri terbimbing lebih menekankan pada siswa untuk aktif melatih keberanian, berkomunikasi dan berusaha mendapatkan pengetahuannya sendiri untuk memecahkan masalah yang dihadapi (Dewi, 2013). Keanekaragaman tumbuhan yang terdapat di lingkungan SMA Negeri 4 Palembang antara lain palem, mangga, bunga bougenvil, dan sebagainya. Selain itu juga terdapat pekarangan dan kolam dimana terdapat juga hewan-hewan di sekitar lingkungan seperti, ikan, burung, kucing dan sebagainya. Penggunaan model inkuiri terbimbing dapat membantu siswa memperoleh pengalaman dengan melakukan penyelidikan atau pengamatan keanekaragaman hayati secara langsung di lingkungan sekolah. Manfaat mengajak siswa mengamati lingkungan sekolah yaitu agar siswa mampu mengenal dan memahami keanekaragaman hayati yang ada di alam sekitar sehingga mereka mampu mengelompokkan tumbuhan dan hewan tersebut sesuai dengan jenis dan ciriciri yang dimilikinya.

\section{METODE PENELITIAN}

Penelitian ini telah dilaksanakan pada Bulan Agustus-September 2017 di SMA Negeri 4 Palembang. Metode yang digunakan adalah metode kuantitatif Quasi Eksperimen dan desain yang digunakan adalah Non equivalent control group design. 
Tabel 1. Nonequivalent Control Group

\begin{tabular}{cccc}
\multicolumn{4}{c}{ Design } \\
\hline Subjek & Pretes & Perlakuan & Postes \\
\hline X MIPA & $\mathrm{O}_{1}$ & $\mathrm{X}$ & $\mathrm{O}_{2}$ \\
1 \\
$\begin{array}{c}\text { X MIPA } \\
2\end{array}$ & $\mathrm{O}_{3}$ & - & $\mathrm{O}_{4}$ \\
\hline
\end{tabular}

\section{Keterangan:}

\begin{tabular}{|c|c|}
\hline X MIPA & $\begin{array}{l}\text { : Subjek penelitian siswa kelas } \mathrm{X} \\
\text { MIPA } 1 \text { (kelas eksperimen) }\end{array}$ \\
\hline X MIPA 2 & $\begin{array}{l}\text { : Subjek penelitian siswa kelas } \mathrm{X} \\
\text { MIPA } 2 \text { (kelas kontrol) }\end{array}$ \\
\hline $\mathrm{O}_{1}$ & $\begin{array}{l}\text { Pemberian tes awal pada kelas } \\
\text { eksperimen }\end{array}$ \\
\hline $\mathrm{O}_{2}$ & $\begin{array}{l}\text { : Pemberian tes akhir pada kelas } \\
\text { eksperimen }\end{array}$ \\
\hline $\mathrm{O}_{3}$ & $\begin{array}{l}\text { : Pemberian tes awal pada kelas } \\
\text { kontrol }\end{array}$ \\
\hline $\mathrm{O}_{4}$ & $\begin{array}{l}\text { : Pemberian tes akhir pada kelas } \\
\text { kontrol }\end{array}$ \\
\hline $\mathrm{X}$ & $\begin{array}{l}\text { : Perlakuan (pemanfaatan lingkungan } \\
\text { sekolah sebagai sumber } \\
\quad \text { belajar dengan model } \\
\text { inkuiri terbimbing) } \\
\text {. }\end{array}$ \\
\hline
\end{tabular}

Teknik sampling yang digunakan adalah purposive sampling, yaitu kelas $\mathrm{X}$ MIPA 1 merupakan kelas eksperimen, dan kelas X MIPA 2 sebagai kelas kontrol. Teknik pengumpulan data yang digunakan dalam penelitian ini adalah Tes pilihan ganda yang berjumlah 24 soal. Teknik analisis data menggunakan uji Paired Sample t-Test.

\section{HASIL DAN PEMBAHASAN}

Adapun sebelum dan setelah melakukan penelitian terhadap kelas eksperimen (X MIPA 1) yang memanfaatkan lingkungan sekolah dengan model inkuiri terbimbing dan kelas kontrol (X MIPA 2) yang menggunakan model konvensional dilakukan pretes dan postes yang bertujuan untuk mengetahui pengetahuan awal siswa tentang konsep keanekaragaman hayati dan untuk mengetahui pengetahuan siswa setelah diajarkan konsep keanekaragaman hayati.
Hasil pretes dan postes dari kedua kelas dapat dilihat pada Tabel 2.

Tabel 2. Nilai Pretes dan Postes Kelas Eksperimen dan Kelas Kontrol

\begin{tabular}{|c|c|c|c|}
\hline & $\begin{array}{c}\text { Nilai } \\
\text { Minimum }\end{array}$ & $\begin{array}{c}\text { Nilai } \\
\text { Maksimum }\end{array}$ & Rata-rata \\
\hline Pretes & 21 & 71 & 49,06 \\
\hline Eksperimen & & & \\
\hline Postes & 75 & 92 & 82,58 \\
\hline Eksperimen & & & \\
\hline Pretes Kontrol & 29 & 63 & 47,06 \\
\hline Postes Kontrol & 54 & 83 & 72,45 \\
\hline
\end{tabular}

Berdasarkan data Tabel 2 tersebut, dapat diketahui bahwa nilai rata-rata postes kelas eksperimen lebih besar dibandingkan dengan nilai rata-rata kelas kontrol. Perbedaan ini juga terlihat sangat jauh jika dibandingkan dengan nilai rata-rata pretes eksperimen dengan nilai rata-rata kelas kontrol.

Selain nilai rata-rata, dapat pula dilihat perbedaan kedua kelas tersebut menggunakan jumlah persentase jawaban pretes postes kelas kontrol dan eksperimen. Data ini dilihat pada setiap level kognitif yang terdiri dari $\mathrm{C} 1-\mathrm{C} 6$ yaitu mengingat, memahami, mengaplikasikan, menganalisis, mengevaluasi, dan mencipta (dapat dilihat pada Tabel 3 dan Tabel 4).

Tabel 3. Persentase Jawaban Pretes Siswa yang Benar pada Hasil Belajar Kognitif Kelas Eksperimen dan Kelas Kontrol

\begin{tabular}{ccc}
\hline \multirow{2}{*}{$\begin{array}{c}\text { Level } \\
\text { kognitif }\end{array}$} & \multicolumn{2}{c}{ Persentase $(\%)$} \\
\cline { 2 - 3 } & $\begin{array}{c}\text { Pretes } \\
\text { Eksperimen }\end{array}$ & $\begin{array}{c}\text { Pretes } \\
\text { Kontrol }\end{array}$ \\
\hline C1 & 67,74 & 62,36 \\
C2 & 59,67 & 58,06 \\
C3 & 43,54 & 49,19 \\
C4 & 44,51 & 43,22 \\
C5 & 50 & 51,61 \\
C6 & 39,24 & 38,70 \\
\hline
\end{tabular}

Ket:

C1: Mengingat 
C2: Memahami

C3: Mengaplikasikan

C4: Menganalisis

C5: Mengevaluasi

C6: Mencipta

Tabel 4. Persentase Jawaban Postes Siswa yang Benar pada Hasil Belajar Kognitif Kelas Eksperimen dan Kelas Kontrol

\begin{tabular}{ccc}
\hline \multirow{2}{*}{ Level kognitif } & \multicolumn{2}{c}{ Persentase (\%) } \\
\cline { 2 - 3 } & $\begin{array}{c}\text { Postes } \\
\text { Eksperimen }\end{array}$ & $\begin{array}{c}\text { Postes } \\
\text { Kontrol }\end{array}$ \\
\hline C1 & 79,56 & 68,81 \\
C2 & 84,69 & 83,06 \\
C3 & 87,09 & 76,61 \\
C4 & 85,80 & 81,29 \\
C5 & 61,29 & 54,83 \\
C6 & 89,24 & 62,90 \\
\hline
\end{tabular}

Persentase hasil belajar kognitif berdasarkan jumlah siswa pada pretes kelas eksperimen lebih tinggi pada indikator $\mathrm{C} 1$, C2, C4 dan C6, sedangkan pada kelas kontrol indikator C3 dan C5 lebih tinggi daripada kelas eksperimen, sedangkan persentase hasil belajar kognitif berdasarkan jumlah siswa pada postes kelas eksperimen pada semua indikator kognitif $\mathrm{C} 1, \mathrm{C} 2, \mathrm{C} 3, \mathrm{C} 4, \mathrm{C} 5$ dan C6 lebih tinggi daripada kelas kontrol. Pada pretes kelas eksperimen dan kontrol, persentase hasil belajar kognitif berdasarkan jumlah siswa pada indikator C1-C6 hampir sama, hal tersebut disebabkan karena pada saat pretes kedua kelas tersebut memang belum diberi perlakuan apapun, tetapi pada postes kelas eksperimen, persentase hasil belajar kognitif pada indikator C1-C6 semua meningkat, hal tersebut disebabkan karena pada kelas eksperimen menggunakan model inkuiri terbimbing dan pada kelas kontrol hanya menggunakan pembelajaran konvensional.

Selanjutnya dilakukan analisis hipotesis uji statistik Paired Sample t-Test. Sebelum dilakukan uji hipotesis, telah 118 dilakukan uji prasyarat yakni uji normalitas dan uji homogenitas nilai pretes dan postes siswa kelas eksperimen dan kelas kontrol. Uji prasyarat normalitas dan homogenitas menunjukkan bahwa nilai pretes dan postes siswa kelas eksperimen dan kontrol berdistribusi normal dan homogen yang selanjutnya dapat dilakukan uji lanjut parametrik yaitu uji t berpasangan (Paired Sample t-Test). Hasil Uji hipotesis ini diperoleh dari perhitungan hasil nilai pretes dan postes siswa yang memanfaatkan lingkungan sekolah dengan model inkuiri terbimbing untuk kelas eksperimen dan pembelajaran konvensional untuk kelas kontrol. Hasil Uji hipotesis dapat dilihat pada Tabel 5.

Tabel 5. Hasil Uji Data Berpasangan Nilai Pretes dan Postes Kelas Eksperimen

\begin{tabular}{llll}
\hline Data & $\begin{array}{l}\text { Standar } \\
\text { Deviasi }\end{array}$ & t-Hitung & $\begin{array}{l}\text { Signifikansi } \\
(2 \text {-tailed })\end{array}$ \\
\hline $\begin{array}{l}\text { Pretes dan } \\
\text { Postes }\end{array}$ & 11,18 & 16,67 & 0,00 \\
Eksperimen & & & \\
\hline
\end{tabular}

Berdasarkan Tabel 5, menunjukkan bahwa standar deviasi data nilai pretes dan postes kelas eksperimen adalah 11,18 dan thitung sebesar 16,67. Menurut kriteria penerimaan hipotesis Ha akan diterima jika signifikansi (2-tailed) lebih kecil dari 0,05. Pada perhitungan pretes dan postes memiliki nilai signifikansi (2-tailed) $0,00<$ 0,05 artinya Ha diterima karena signifikansi (2-tailed) lebih kecil dari 0,05. Maka dapat diartikan bahwa terdapat perbedaan antara nilai pretes dan postes siswa pada kelas eksperimen sehingga dikatakan bahwa pemanfaatan lingkungan sekolah sebagai sumber belajar dengan model inkuiri terbimbing berpengaruh terhadap hasil belajar siswa pada konsep keanekaragaman hayati kelas $\mathrm{X}$ di SMA Negeri 6 Palembang. 
Berdasarkan hasil uji hipotesis pada Tabel 5, nilai kognitif diketahui bahwa pemanfaatan lingkungan sekolah sebagai sumber belajar dengan model inkuiri terbimbing berpengaruh terhadap hasil belajar siswa. Berdasarkan perhitungan uji t berpasangan (Paired Sample t-test) diketahui hasil belajar siswa pada ranah kognitif pada kelas eksperimen dengan memanfaatkan lingkungan sekolah sebagai sumber belajar dengan model inkuiri terbimbing lebih baik dibanding dengan kelas kontrol dengan model konvensional yang sering digunakan guru pada pembelajaran biasanya. Subyek yang digunakan dalam penelitian ini adalah kelas X MIPA 1 sebagai kelas eksperimen dan kelas X MIPA 2 sebagai kelas kontrol di SMA Negeri 4 Palembang.

Hasil belajar kognitif siswa pada kelas eksperimen mengalami peningkatan karena peneliti menggunakan model pembelajaran inkuiri terbimbing dalam proses pembelajaran. Model pembelajaran inkuiri terbimbing dapat meningkatkan hasil belajar kognitif siswa kelas eksperimen karena model ini memberi kesempatan kepada siswa untuk berlatih mengembangkan keterampilan berpikir berdasarkan penentuan rumusan masalah dan penentuan hipotesis yang diberikan guru dalam lembar kerja siswa, sehingga siswa akan dapat meningkatkan pemahamannya pada materi yang dipelajari. Hal ini sejalan dengan pendapat Sandi (2015) yang menyatakan bahwa model inkuiri terbimbing dapat meningkatkan pemahaman siswa dengan melibatkan siswa dalam proses kegiatan pembelajaran secara aktif, sehingga konsep yang dicapai lebih baik.

Meningkatnya hasil belajar kognitif siswa kelas eksperimen tidak hanya karena model inkuiri terbimbing saja, tetapi juga karena penggunaan lingkungan sekolah sebagai sumber belajar. Manfaat dari mengajak siswa ke lingkungan sekolah yaitu dapat memberikan kemudahan kepada siswa dalam memperoleh informasi dan pengetahuan tentang keanekaragaman hayati secara nyata, serta memberi kesempatan kepada siswa untuk mempelajari cara menemukan fakta, konsep, dan prinsip melalui pengalamannya secara langsung, sehingga ilmu yang diperoleh dapat tertanam dalam ingatan dan benak siswa dalam jangka panjang. Hal ini sejalan dengan pendapat Istiani (2015) yang menyatakan bahwa keanekaragaman makhluk hidup di lingkungan sekitar mempermudah siswa mengamati berbagai jenis makhluk hidup dengan seluruh panca indera. Selanjutnya pendapat Pantiwati (2015) menyatakan bahwa lingkungan secara alami mendorong anak untuk berinteraksi dengan komponennya, seperti dengan tumbuhan, hewan, atau manusia, dan benda mati di sekitar lingkungan.

Hasil belajar kognitif pada siswa kelas kontrol juga mengalami peningkatan, tetapi hasil belajar kognitif siswa kelas eksperimen lebih baik dibandingkan dengan kelas kontrol. Hal tersebut dibuktikan pada perhitungan nilai rata-rata postes kelas kontrol yaitu hanya 72,45 , sedangkan nilai rata-rata postes kelas eksperimen yaitu 82,58 . Proses pembelajaran di kelas kontrol yakni menggunakan model konvensional, dimana pada pembelajarannya lebih terpusat kepada guru. Siswa lebih banyak mendengarkan penyampaian materi dari guru, hal ini menyebabkan siswa kurang semangat belajar karena merasa bosan dengan cara belajarnya dan mengakibatkan hasil belajar kognitif yang kurang baik. Pada kelas kontrol juga siswa tidak diajak 
keluar kelas seperti kelas eksperimen untuk mengamati keanekaragaman hayati secara langsung, siswa hanya belajar di dalam kelas dengan memperoleh informasi dari penjelasan guru serta mendapatkan materi dari buku paket dan internet, sehingga hal inilah yang membuat ingatan siswa mengenai materi yang telah dipelajari menjadi singkat dan siswa cepat lupa dengan materi pelajaran yang telah dipelajari.

\section{PENUTUP}

Berdasarkan hasil penelitian dan analisis data, maka dapat disimpulkan bahwa pemanfaatan lingkungan sekolah sebagai sumber belajar dengan model inkuiri terbimbing dapat memberikan pengaruh terhadap hasil belajar biologi siswa pada konsep keanekaragaman hayati kelas X di SMA Negeri 4 Palembang. Hal ini dapat dilihat dari hasil perhitungan pretes dan postes pada kelas eksperimen yang memiliki nilai signifikansi (2-tailed) $0,000<0,05$. Artinya terdapat perbedaan antara nilai pretes dan postes siswa pada kelas eksperimen sehingga dikatakan bahwa pemanfaatan lingkungan sekolah sebagai sumber belajar dengan model inkuiri terbimbing berpengaruh terhadap hasil belajar siswa pada konsep keanekaragaman hayati kelas $\mathrm{X}$ di SMA Negeri 4 Palembang.

Saran bagi Guru yang akan menggunakan model Inkuiri Terbimbing hendaknya memberikan LKS sesuai dengan yang akan dipelajari sehingga dapat mempermudah siswa dalam melaksanakan proses belajar.

\section{DAFTAR PUSTAKA}

Anni, C.T. (2006). Psikologi Belajar. Semarang: UPT MKK UNNES.

Brahim, T.K. (2007). Peningkatan Hasil Belajar Sains Siswa Kelas IV Sekolah Dasar, Melalui Pendekatan Pemanfaatan Sumber Daya Alam Hayati di Lingkungan Sekitar. Jurnal Pendidikan Penabur, (9), 37-49.

Dewi, N.L., Dantes, N., \& Sadia, I.W. (2013). Pengaruh Model Pembelajaran Inkuiri Terbimbing Terhadap Sikap Ilmiah dan Hasil Belajar IPA. $e^{-} \quad$ Journal Program Pascasarjana Universitas Pendidikan Ganesha, (3).

Hamalik, O. (2009). Kurikulum dan Pembelajaran. Jakarta: PT. Bumi Aksara.

Istiani, R.M., \& Retnoningsih, A. (2015). Pemanfaatan Lingkungan Sekolah Sebagai Sumber Belajar Menggunakan Metode Post To Post pada Materi Klasifikasi Makhluk Hidup. Unnes Journal Of Biology Education, 4 (1), 70-80.

Kemdikbud. (2017). (Rekap Hasil Ujian Nasional (UN) Tingkat Sekolah). (Online). (https://puspendik.kemdikbud.go.id/ hasilun/). Diakses pada Rabu, 15 November 2017.

Kurniawan, A.D. (2013). Metode Inkuiri Terbimbing dalam Pembuatan Media Pembelajaran Biologi untuk Meningkatkan Pemanfaatan Konsep dan Kreativitas Siswa SMP. Jurnal Pendidikan IPA Indonesia, 2 (1).

Machin, A. (2014). Implementasi Pendekatan Saintifik, Penanaman Karakter dan Konservasi pada Pembelajaran Materi Pertumbuhan. Jurnal Pendidikan IPA Indonesia. 3 (1), 28-35.

Nugroho, A. A., \& Hanik, N. R. (2016). Implementasi Outdoor Learning untuk Meningkatkan Hasil Belajar Kognitif Mahasiswa pada Mata Kuliah Sistematika Tumbuhan Tinggi. Bioedukasi: Jurnal Pendidikan Biologi, 9(1), 41-44.

Pantiwati, Y. (2015). Pemanfaatan Lingkungan Sekolah Sebagai Sumber Belajar dalam Lesson Study untuk Meningkatkan Metakognitif. Jurnal Bioedukatika, 3 (1), 27-32.

Rahayu, E., Susanto, H., \& Yulianti, D. (2011). Pembelajaran Sains dengan Pendekatan Keterampilan Proses untuk Meningkatkan Hasil Belajar dan Kemampuan Berpikir Kreatif Siswa. Jurnal Pendidikan Fisika Indonesia. 7, 106-110.

Ramawati, I., Maryani, E., \& dan Mulyana, A. (2016). Pemanfaatan Lingkungan Sekitar Sebagai Sumber Pembelajaran untuk Meningkatkan Kemampuan Berfikir Kritis. Jurnal Pendidikan Geografi, 16 (1), 66-87. 
Sandi, T. (2015). Hasil Belajar Kimia Melalui Pemanfaatan Lingkungan sebagai Sumber Belajar dengan Model Pembelajaran Inkuiri Terbimbing. Jurnal Nalar Pendidikan. 3 (1), 205-211.

Setiawan, I.G.A.N. (2008). Penerapan Pengajaran Kontekstual Berbasis Masalah untuk Meningkatkan Hasil Belajar Biologi Siswa Kelas $\mathrm{X}_{2}$ SMA Laboratorium Singaraja. Jurnal Pendidikan dan Pengembangan Pendidikaan, 2 (1), 42-59.

Sjukur, S.B. (2012). Pengaruh Blended Learning Terhadap Motivasi dan hasil Belajar Siswa Tingkat SMK. Jurnal Pendidikan Vokasi, 2 (3), 368-378 